\title{
Schisandrin B attenuates pressure overload-induced cardiac remodeling in mice by inhibiting the MAPK signaling pathway
}

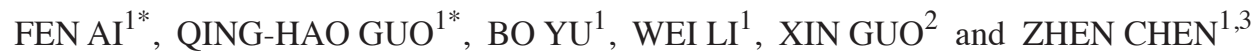 \\ Departments of ${ }^{1}$ Emergency, ${ }^{2}$ Cardiovascular Medicine, and ${ }^{3}$ Evidence-Based Medicine, The Central Hospital of Wuhan, \\ Tongji Medical College, Huazhong University of Science and Technology, Wuhan, Hubei 430014, P.R. China
}

Received April 2, 2019; Accepted October 4, 2019

DOI: $10.3892 /$ etm.2019.8154

\begin{abstract}
The aim of the current study was to investigate the effect and mechanism of schisandrin B (Sch B) on myocardial hypertrophy induced by pressure overload in mice. Male C57BL/6J mice were randomly divided into three groups: i) Sham $(n=12)$; ii) transverse aortic constriction (TAC) $(\mathrm{n}=12)$; and iii) Sch B-treated $\left(\mathrm{n}=12 ; 80 \mathrm{mg} \cdot \mathrm{kg}^{-1} \cdot \mathrm{d}^{-1}\right.$ per gavage). The model of myocardial hypertrophy was established by constricting the descending branch of the aortic arch. Following a 4-week treatment period, cardiac remodeling was evaluated using echocardiography and pathological and molecular analysis. Sch B improved cardiac function in the Sch B-treated group compared with the TAC group. Moreover, the Sch B-treated group had a smaller myocardial cell cross-sectional area and less fibrosis compared with the TAC group. The protein expression levels of cardiac hypertrophy and fibrosis markers in the TAC group were significantly higher compared with those in the sham group. The same markers in the Sch B-treated group were significantly lower compared with those in the TAC group. Additionally, the phosphorylation levels of the mitogen-activated protein kinase (MAPK) signaling pathway-associated proteins extracellular signal-regulated kinase $1 / 2$, c-Jun N-terminal kinase $1 / 2$ and P38 mitogen-activated protein kinase were significantly lower in the Sch B-treated group compared with the TAC group. Further in vitro investigation demonstrated that Sch B
\end{abstract}

Correspondence to: Dr Xin Guo, Department of Cardiovascular Medicine, The Central Hospital of Wuhan, Tongji Medical College, Huazhong University of Science and Technology, 26 Shengli Street, Wuhan, Hubei 430014, P.R. China

E-mail: syzsyz123321@outlook.com

Dr Zhen Chen, Department of Emergency, The Central Hospital of Wuhan, Tongji Medical College, Huazhong University of Science and Technology, 26 Shengli Street, Wuhan, Hubei 430014, P.R. China E-mail: wenwen120866@126.com

\section{*Contributed equally}

Key words: schisandrin B, cardiac hypertrophy, myocardial fibrosis, mitogen-activated protein kinase signaling pathway prevented the adverse effects of angiotensin II-induced hypertrophy and fibrosis by inhibiting the MAPK signaling pathway in $\mathrm{H} 9 \mathrm{c} 2$ cells. In conclusion, Sch B may improve pathological myocardial remodeling and cardiac function induced by pressure overload, and its underlying mechanism may be associated with inhibition of the MAPK signaling pathway.

\section{Introduction}

Heart failure (HF) is the leading cause of death worldwide (1). Hypertension the most important independent risk factor for HF, which may result in pathological left ventricular (LV) hypertrophy and myocardial fibrosis (2-5). Previous studies have revealed that inhibiting or reversing cardiac hypertrophy may be an effective treatment for preventing LV remodeling and HF (6-8). Therefore, there is a requirement for the identification of novel drugs that improve pathological myocardial remodeling in patients with $\mathrm{HF}$.

Schisandrin B (Sch B) is the most abundant and potent ingredient isolated from the fruit of Schisandra spp. and is a popular Chinese herbal medicine (9). Sch B exhibits a number of pharmacological effects, including anti-inflammatory, antioxidative and anticancer effects (10-12). A previous study indicated that Sch B exhibits anti-inflammatory activity via modulation of the redox-sensitive transcription factors Nrf2 and NF- $\kappa$ B (11). A study performed by Ip et al (10) demonstrated that Sch B protects against carbon tetrachloride toxicity through enhanced the function of the hepatic glutathione antioxidant system. A number of studies have indicated that $\mathrm{Sch} \mathrm{B}$ serves a vital role in cardiovascular disease. A report by Thandavarayan et al (13) has demonstrated that Sch B prevents doxorubicin induced cardiac dysfunction by modulation of DNA damage, oxidative stress and inflammation through inhibition of MAPK/p53 signaling. Furthermore, Chen et al (14) observed that Sch B reduces inflammation, inhibits apoptosis, and improves cardiac function following myocardial infarction. A number of studies have consistently demonstrated that Sch B ameliorates myocardial ischemia-reperfusion injury $(15,16)$. However, the mechanism of action of Sch B in stress-induced pathological cardiac hypertrophy has not been investigated. The aim of the present study was therefore to investigate the protective effect of Sch B on stress-induced pathological cardiac hypertrophy and to elucidate its underlying mechanism. 


\section{Materials and methods}

Experimental animals. All in vivo experiments were approved by the Animal Care and Use Committee of the Central Hospital of Wuhan. The 36 C57BL/6 mice (male; age, 7-8 weeks; weight, 22-26 g) were purchased from Beijing HFK Bioscience Co., Ltd. Mice were housed in an environment with controlled light cycles $\left(12 \mathrm{~h}\right.$ light/dark), temperature $\left(20-24^{\circ} \mathrm{C}\right)$ and humidity (45-55\%). Food and water were provided ad libitum.

Mouse model and experimental grouping. Surgeries and subsequent analyses were performed in a blinded manner. Aortic banding $(n=24)$ and sham $(n=12)$ surgeries were performed as previously described (17). Briefly, 36 mice were anesthetized with an intraperitoneal injection of $3 \%(50 \mathrm{mg} / \mathrm{kg})$ sodium pentobarbital solution. The depth of anesthesia during the surgical procedures was assessed via the pedal withdrawal reflex and breathing rate. An incision was made on the left side of the chest of each mouse and the thoracic aorta was identified by blunt dissection at the second intercostal space. A 26-G needle was placed on the thoracic aorta and a 7-0 silk suture was placed around the thoracic aorta and needle, and tied. The needle was withdrawn immediately after successful ligation, resulting in a transverse aortic constriction (TAC). Doppler analysis was subsequently performed to ensure that the aorta had been adequately constricted. The thoracic aortas of the animals in the sham group were threaded but not ligated.

Sch B treatment protocol in vivo. Sch B (purity $\geq 97 \%$ ) was purchased from Shanghai PureOne Biotechnology Co., Ltd. and dissolved in olive oil. Oral administration is currently the main route of administration of Sch B in clinical practice (9). Therefore, in order to better simulate clinical treatment, the mice in the current study were administered Sch B intragastrically. Furthermore, intragastric administration of Sch B has previously been reported by Chen et al (14). A study on the pharmacokinetics of Sch B revealed that the calculated absolute oral bioavailability of Sch B was $\sim 55.0 \%$ for female rats and $19.3 \%$ for male rat (18). A number of studies also support the good oral bioavailability of Sch B in mice $(19,20)$. Therefore, SchB was not decomposed or destroyed by gastric acid. Following ligation of the thoracic aorta, animals in the Sch B group $(\mathrm{n}=12)$ received $80 \mathrm{mg} / \mathrm{kg}$ Sch B intragastrically per day for 4 weeks. Animals in the TAC $(n=12)$ and sham $(n=12)$ groups received the same volume of olive oil daily.

Echocardiography analysis. The mice were anesthetized with $1.5-2 \%$ isoflurane and echocardiography using a Mylab30CV (Esaote Group) ultrasound system with a $15-\mathrm{Mz}$ probe was performed, 4 weeks after the TAC. The short-axis view of the standard left ventricular papillary muscle was selected, and the left ventricular end-systolic diameter (LVESd), left ventricular end-diastolic diameter (LVEDd), left ventricular ejection fraction (LVEF) and left ventricular fractional shortening (LVFS) were measured. Following echocardiography, the mice were sacrificed via an overdose of sodium pentobarbital $(200 \mathrm{mg} / \mathrm{kg})$ injected intraperitoneally. The body weight (BW), heart weight (HW), lung weight (LW) and tibia length (TL) were measured. HW/BW, LW/BW and HW/TL values were subsequently calculated.
Myocardial histopathology. The heart was removed from the sacrificed animals and placed in $10 \%$ potassium chloride to extrude the blood from the heart cavity. Tissues were subsequently fixed in $4 \%$ paraformaldehyde at $4^{\circ} \mathrm{C}$ for $12 \mathrm{~h}$, dehydrated with a descending alcohol series $(100 \%$ alcohol for $5 \mathrm{~min}, 95 \%$ alcohol for $5 \mathrm{~min}$ and $75 \%$ alcohol for $5 \mathrm{~min}$ ), embedded in paraffin and sectioned. Cross-sections of the LV papillary muscle were prepared, and 4-5 mm-thick heart sections were subjected to conventional hematoxylin-eosin (H\&E; hematoxylin for $10 \mathrm{~min}$ and eosin for $5 \mathrm{~min}$ at room temperature) and Masson staining (alkali fuchsine solution for $3 \mathrm{~min}$, phosphomolybdic acid for $1 \mathrm{~min}$, and aniline blue solution for $2 \mathrm{~min}$ at room temperature). Sections were observed under a microscope and Image Pro Plus software (version 6.0; Media Cybernetics, Inc.) was used to calculate the myocardial cell cross-sectional area (CSA) and the area of the fibrotic region in the $\mathrm{LV}$.

Cell culture and angiontensin II (Ang II) treatment. The rat cardiomyocyte cell line H9c2 was purchased from the The Cell Bank of Type Culture Collection of the Chinese Academy of Sciences and cultured in DMEM (Gibco; Thermo Fisher Scientific, Inc.) supplemented with 10\% FBS (Gibco; Thermo Fisher Scientific, Inc.), $2 \mathrm{mmol} / \mathrm{l}$ glutamine, $1 \mathrm{mmol} / \mathrm{l}$ pyruvate, $100 \mathrm{U} / \mathrm{ml}$ penicillin and $100 \mathrm{mg} / \mathrm{ml}$ streptomycin. Cells were maintained in a humidified incubator at $37^{\circ} \mathrm{C}$ and $5 \% \mathrm{CO}_{2}$.

Previous studies indicated that pretreatment with Sch B at concentration of 5-20 $\mu \mathrm{M}$ for 16-24 h resulted in optimal myocardial protection against ischemic injury in vitro $(14,21)$. In the current study, cells were pretreated with Sch B (5, 10 and $20 \mu \mathrm{M}$ ) for $16 \mathrm{~h}$ at room temperature. The cells were subsequently treated with Ang II dissolved in DMSO to a final concentration of $1 \mu \mathrm{M}$ for $30 \mathrm{~min}$ at room temperature. DMSO was used as the vehicle control. Cell viability was measured using the MTT assay, which relies on the ability of living cells to convert thiazole blue into purple formazan. The optical density of the formazan was subsequently detected at a wavelength of $570 \mathrm{~nm}$. The results were normalized to those of the untreated control. Protein and mRNA expression levels in the treated and control cells were analyzed by western blot analysis and reverse-transcription quantitative PCR (RT-qPCR), respectively.

Western blot analysis. Total proteins were extracted from LV tissues and H9c2 cells using lysis buffer containing Protease Inhibitor Cocktail (cat. no. 04693159001; Roche Diagnostics), Phenylmethanesulfonyl Fluoride (cat. no. AS1006; Aspen) and Phosphatase Inhibitor (cat. no. AS1008; Aspen). Extracted proteins were subjected to centrifugation $\left(13,000 \mathrm{x} \mathrm{g} ; 4^{\circ} \mathrm{C}\right.$; $5 \mathrm{~min}$ ), sonication ( $20 \mathrm{kHz}$; room temperature; $10 \mathrm{sec} ; 3$ times) and heat denaturation. The total protein concentration was determined using the BCA Protein Assay kit (cat. no. P0010; Beyotime Institute of Biotechnology). Proteins (40 $\mu \mathrm{g} / \mathrm{lane})$ were separated on an 8-10\% SDS-PAGE gel and transferred onto a polyvinylidene fluoride membrane, which was subsequently incubated with primary antibodies overnight at $4^{\circ} \mathrm{C}$. Following primary antibody incubation, the membrane was incubated with GAPDH (1:10,000; cat. no. ab37168; Abcam) for $2 \mathrm{~h}$ at room temperature. The antibodies used in the current study are presented in Table I. Protein bands were detected 
Table I. Mouse primary antibodies for western blotting.

\begin{tabular}{|c|c|c|c|c|}
\hline Antibody & Source organism & Supplier & Dilution & Cat. no. \\
\hline ANP & Rabbit & Abcam & $1: 1,000$ & $a b 225844$ \\
\hline $\mathrm{BNP}$ & Rabbit & Abcam & $1: 1,000$ & $\mathrm{ab} 236101$ \\
\hline$\beta-\mathrm{MHC}$ & Mouse & Abcam & $1: 500$ & ab11083 \\
\hline Collagen I & Rabbit & Abcam & $1: 500$ & ab34710 \\
\hline CTGF & Rabbit & Abcam & $1: 1,000$ & ab6992 \\
\hline Collagen III & Rabbit & Abcam & $1: 1,000$ & ab7778 \\
\hline P-ERK1/2 & Rabbit & Cell Signaling Technology, Inc. & $1: 1,000$ & \#4370 \\
\hline ERK1/2 & Rabbit & Cell Signaling Technology, Inc. & $1: 2,000$ & \#4695 \\
\hline P-JNK1/2 & Rabbit & Cell Signaling Technology, Inc. & $1: 1,000$ & \#4671 \\
\hline JNK1/2 & Rabbit & Cell Signaling Technology, Inc. & $1: 1,000$ & \#9252 \\
\hline P-P38 & Rabbit & Cell Signaling Technology, Inc. & $1: 1,000$ & \#4511 \\
\hline P38 & Rabbit & Cell Signaling Technology, Inc. & $1: 2,000$ & ab170099 \\
\hline GAPDH & Rabbit & Abcam & $1: 10,000$ & ab37168 \\
\hline
\end{tabular}

ANP, atrial natriuretic peptide; BNP, brain natriuretic peptide; $\beta$-MHC, beta-myosin heavy chain; CTGF, connective tissue growth factor; ERK, extracellular signal-regulated kinase; JNK, c-Jun N-terminal kinase; P38, P38 mitogen-activated protein kinase; p, phosphorylated.

using chemiluminescence (cat. no. NCI 5079; Thermo Fisher Scientific, Inc.). Gray-scale scanning and quantification were performed using Image $\mathrm{J}$ software (version 1.32; National Institutes of Health).

$R T-q P C R$. Total RNA was extracted from H9c2 cells using TRIzol ${ }^{\circledR}$ reagent (cat. no. 15596-026; Thermo Fisher Scientific, Inc.) and was reversed transcribed into cDNA using the PrimeScript RT reagent kit (cat. no. RR047A; Takara Biotechnology Co., Ltd.). The temperature protocol was $25^{\circ} \mathrm{C}$ for $10 \mathrm{~min}, 50^{\circ} \mathrm{C}$ for $60 \mathrm{~min}, 90^{\circ} \mathrm{C}$ for $5 \mathrm{~min}$, and $4^{\circ} \mathrm{C}$ for $10 \mathrm{~min}$. RT-qPCR was subsequently performed using a $20 \mu \mathrm{l}$ reaction system containing cDNA, forward and reverse primers and SYBR ${ }^{\circledR}$ Premix Ex Taq (cat. no. RR420A; Takara Biotechnology Co., Ltd.). The initial denaturation was $95^{\circ} \mathrm{C}$ for $30 \mathrm{sec}, 40$ cycles of denaturation at $95^{\circ} \mathrm{C}$ for $5 \mathrm{sec}$, annealing at $60^{\circ} \mathrm{C}$ for $30 \mathrm{sec}$ and elongation at $72^{\circ} \mathrm{C}$ for $30 \mathrm{sec}$, and a final elongation at $72^{\circ} \mathrm{C}$ for $10 \mathrm{~min}$. GAPDH was used as an internal reference gene and presented as an expression fold change using the $2^{-\Delta \Delta \mathrm{Cq}}$ method (22). The primers were synthesized by Shanghai GenePharma Co., Ltd. The sequences of the primers used for RT-qPCR are presented in Table II.

Statistical analysis. SPSS statistical software (version 21; IBM Corp.) was used to conduct all the data analysis. The results are expressed as the mean \pm SEM. Each experiment was repeated four times. Statistical comparisons among multiple groups were performed with one-way ANOVA followed by Tukey's post hoc test. $\mathrm{P}<0.05$ was considered to indicate a statistically significant difference.

\section{Results}

Cardiac function and structure. No deaths were observed in the mice during the 4 -week experimental period. Fig. 1A shows the representative mouse M-mode echocardiograms in each group. The LVEDd and LVESd were significantly lower in the Sch B-treated group compared with the TAC group $(\mathrm{P}<0.05$; Fig. 1B and C). The LVEF and LVFS were significantly higher in the Sch B-treated group compared with the TAC group $(\mathrm{P}<0.05$; Fig. 1D and E). In addition, the HW/BW, HW/TL and $\mathrm{LW} / \mathrm{BW}$ values of the Sch B-treated group were significantly lower compared with the TAC group $(\mathrm{P}<0.05$; Fig. 1F-H).

Cardiac hypertrophy. $\mathrm{H} \& \mathrm{E}$ staining revealed that the cardiomyocyte CSA in the TAC group was increased compared with that in the sham group, while that in the Sch B-treated group was significantly decreased compared with the TAC group $(\mathrm{P}<0.05$; Fig. $2 \mathrm{~A}$ and $\mathrm{B})$. Similarly, western blotting demonstrated that the expression levels of cardiac hypertrophy markers [atrial natriuretic peptide (ANP), brain natriuretic peptide (BNP) and $\beta$-myosin heavy chain $(\beta-\mathrm{MHC})]$ in the TAC group were significantly increased compared with the sham group $(\mathrm{P}<0.05)$. The levels of the aforementioned markers were significantly decreased in the Sch B group compared with the TAC group ( $\mathrm{P}<0.05$; Fig. $2 \mathrm{C}$ and $\mathrm{D})$.

Myocardial fibrosis. Masson staining revealed that the area of LV fibrosis in the Sch B-treated group was significantly decreased compared with that in the TAC group. The staining was significantly lighter in the Sch B-treated group compared with the TAC group ( $\mathrm{P}<0.05$; Fig. $3 \mathrm{~A}$ and $\mathrm{B})$. Similarly, western blotting revealed that the expression levels of the myocardial fibrosis markers connective tissue growth factor (CTGF) and collagen I and III in the TAC group were significantly increased compared with the sham group $(\mathrm{P}<0.05)$. The levels of CTGF and collagen I and III were significantly decreased in the Sch B group compared with the TAC group $(\mathrm{P}<0.05$; Fig. 3C and D).

Sch B improves LV structural remodeling by inhibiting the $M A P K$ signaling pathway. The current study investigated 
Table II. Mouse primers for reverse transcription-quantitative PCR.

\begin{tabular}{lll}
\hline Gene & \multicolumn{1}{c}{ Forward primer $\left(5^{\prime}-3^{\prime}\right)$} & Reverse primer $\left(5^{\prime}-3^{\prime}\right)$ \\
\hline Collagen I & AACAAGGGAGGAGAGAGTGC & AGTCTCTTGCTTCCTCCCAC \\
Collagen III & GAAGGGCAGGGAACAACTGA & GGGCAGTCTAGTGGCTCATC \\
CTGF & CTGTGGGAGAAAACACCCCA & CACTCTTCCAGGAGGCTCAC \\
ANP & ATTGACAGGATTGGAGCCCA & CAGAGTGGGAGAGGTAAGGC \\
BNP & AGTCCTAGCCAGTCTCCAGA & AGTCCTAGCCAGTCTCCAGA \\
$\beta-\mathrm{MHC}$ & GGAGGAGATCAGTGAGAGGC & GCTTCACCCGCTGTAGATTG \\
GAPDH & TGAAGGGTGGAGCCAAAAG & AGTCTTCTGGGTGGCAGTGAT
\end{tabular}

CTGF, connective tissue growth factor; ANP, atrial natriuretic peptide; BNP, brain natriuretic peptide; $\beta$-MHC, $\beta$-myosin heavy chain.
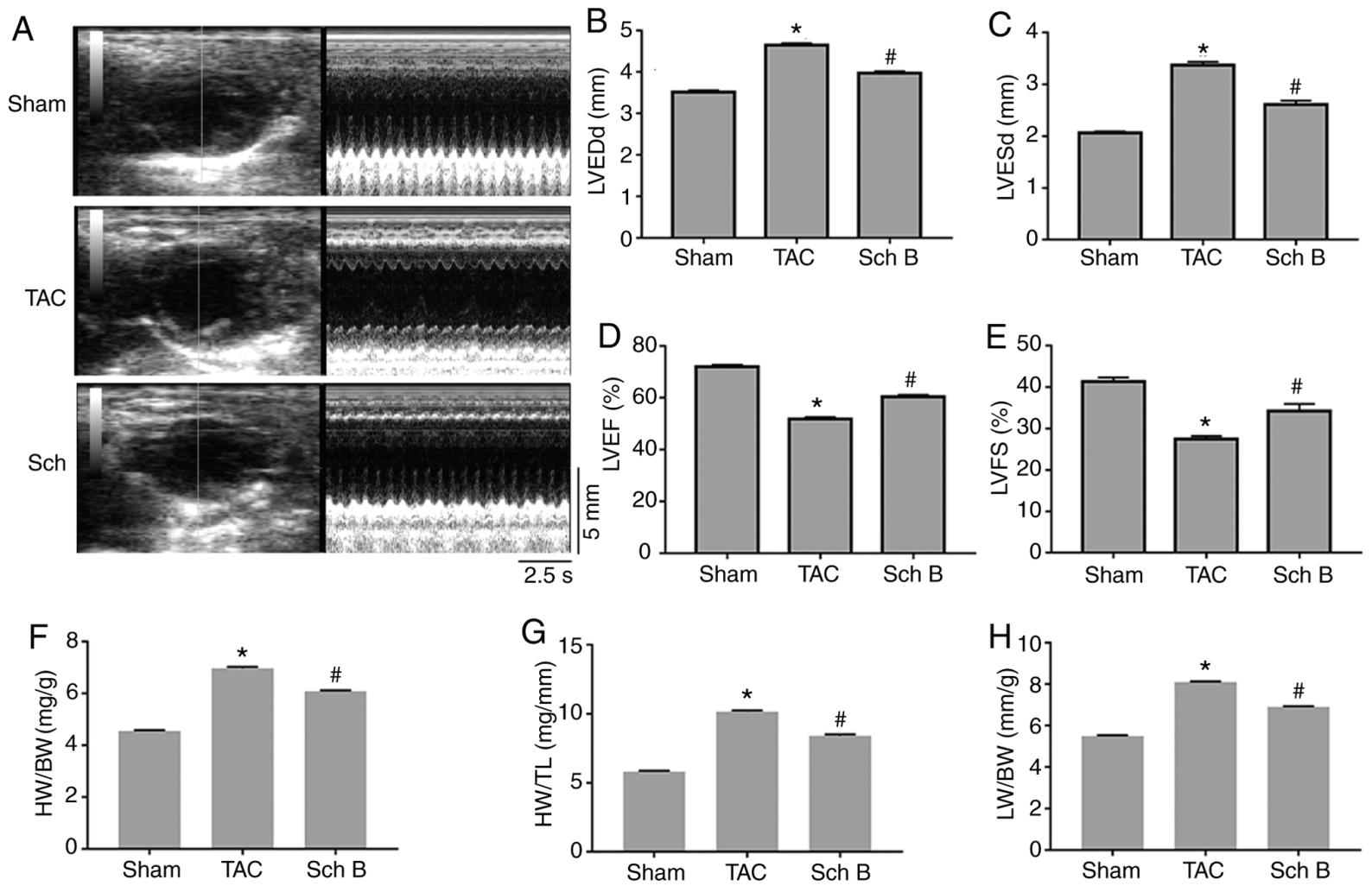

Figure 1. Cardiac function and structure of the mice in each experimental group. (A) Representative mouse M-mode echocardiograms. (B) LVEDd, (C) LVESd, (D) LVEF and (E) FS values of the mice in each group are presented $(n=8)$. (F) HW/BW, (G) HW/TL and (H) LW/BW values of the mice in each group are presented $(\mathrm{n}=6)$. Data are expressed as the mean \pm SEM. ${ }^{*} \mathrm{P}<0.05$ vs. sham; ${ }^{~} \mathrm{P}<0.05$ vs. TAC. LVESd, left ventricular end-systolic diameter; LVEDd, left ventricular end-diastolic diameter; LVEF, left ventricular ejection fraction; LVFS, left ventricular fractional shortening; HW, heart weight; BW, body weight; TL, tibia length; LW, lung weight; TAC, transverse aortic constriction; Sch B, schisandrin B.

the effect of Sch B on the MAPK signaling pathway during pathological myocardial remodeling following TAC. The phosphorylation levels of the MAPK signaling pathway-associated proteins ERK1/2, JNK1/2 and P38 in the myocardial tissue of the Sch-B-treated animals were significantly decreased compared with the TAC group $(\mathrm{P}<0.05$; Fig. 4). These data suggested that Sch B inhibited the MAPK signaling pathway following TAC.

In order to investigate the modulating effect of Sch B on MAPK signaling, different concentrations of Sch B were used to pretreat $\mathrm{H} 9 \mathrm{c} 2$ cells prior to Ang II stimulation. Cell viability was determined using MTT assay is presented in Fig. 5A. There was no difference in cell viability among the different concentrations $(0,5,10$ and $20 \mu \mathrm{M})$ of Sch B. The protein phosphorylation levels of ERK1/2, JNK1/2 and P38 were increased following Ang II stimulation, which was significantly suppressed by 10 and $20 \mu \mathrm{M}$ Sch B compared with the untreated controls $(\mathrm{P}<0.05$; Fig. $5 \mathrm{~B}$ and $\mathrm{C})$. The mRNA levels of the hypertrophy markers ANP, BNP and $\beta$-MHC and the fibrosis mediators CTGF and collagen I and III, induced by Ang II stimulation, were significantly decreased by 10 and $20 \mu \mathrm{M}$ Sch B compared with the untreated controls $(\mathrm{P}<0.05$; Fig. 5D and E). This suggested that the inactivation of the MAPK signaling pathway reduced the pathological remodeling induced by Ang II stimulation. 

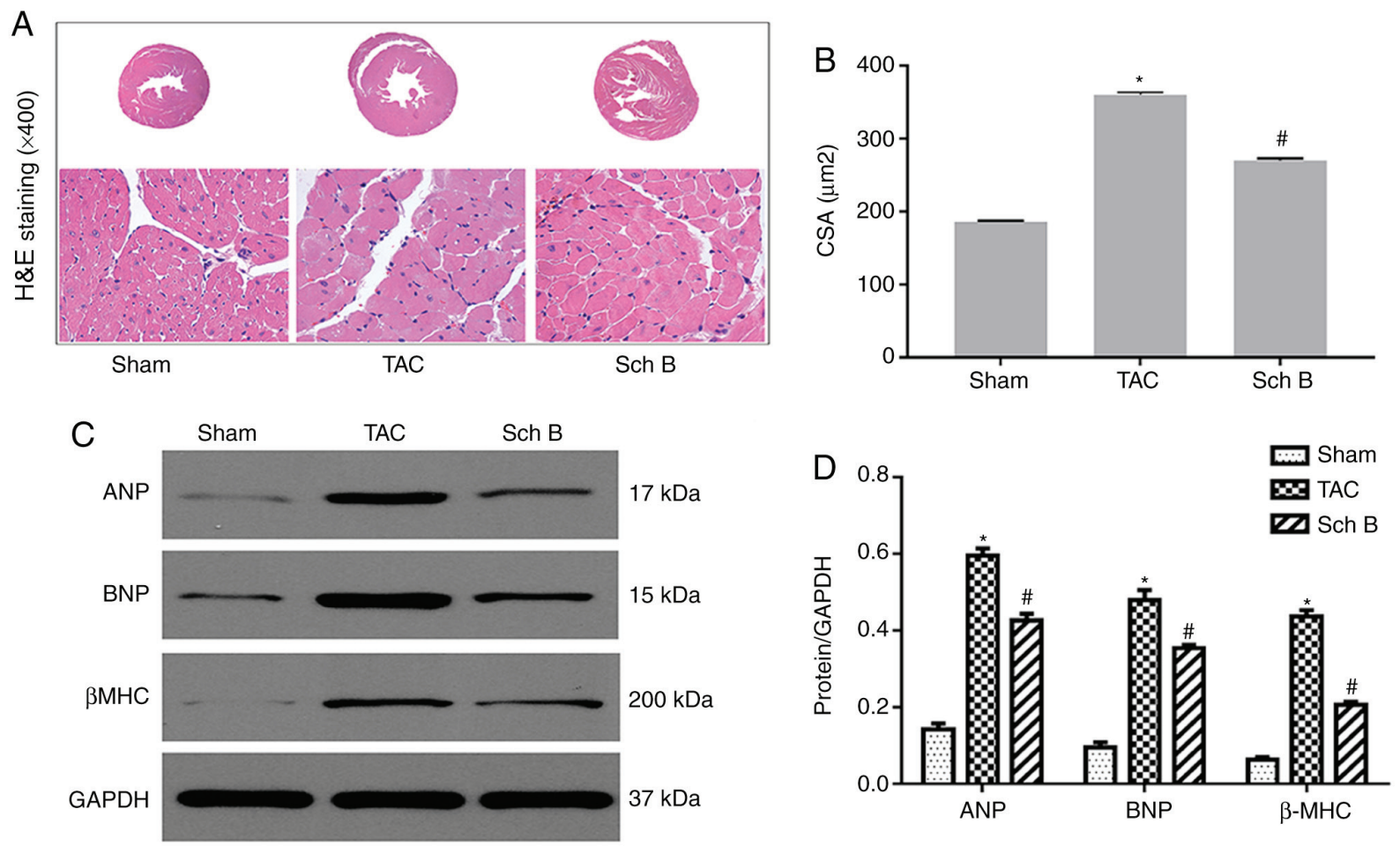

Figure 2. Cardiac hypertrophy levels in each experimental group. (A) Representative H\&E staining of left ventricular tissues obtained from mice in each group (magnification, x400). (B) Statistical analysis of the cardiomyocyte CSA from H\&E-stained sections ( $\mathrm{n}=100+$ cardiomyocytes in four samples). (C) Representative western blotting of the cardiac hypertrophy markers ANP, BNP and $\beta$-MHC in each group. (D) Representative statistical analysis of the cardiac hypertrophy markers ANP, BNP and $\beta$-MHC in each group $(n=4)$. Data are expressed as the mean \pm SEM. "P $<0.05$ vs. respective sham group; ${ }^{\text {}} \mathrm{P}<0.05$ vs. respective TAC group. H\&E, hematoxylin-eosin; CSA, cross-sectional area; ANP, atrial natriuretic peptide; BNP, brain natriuretic peptide; $\beta$-MHC, $\beta$-myosin heavy chain; TAC, transverse aortic constriction; Sch B, schisandrin B.
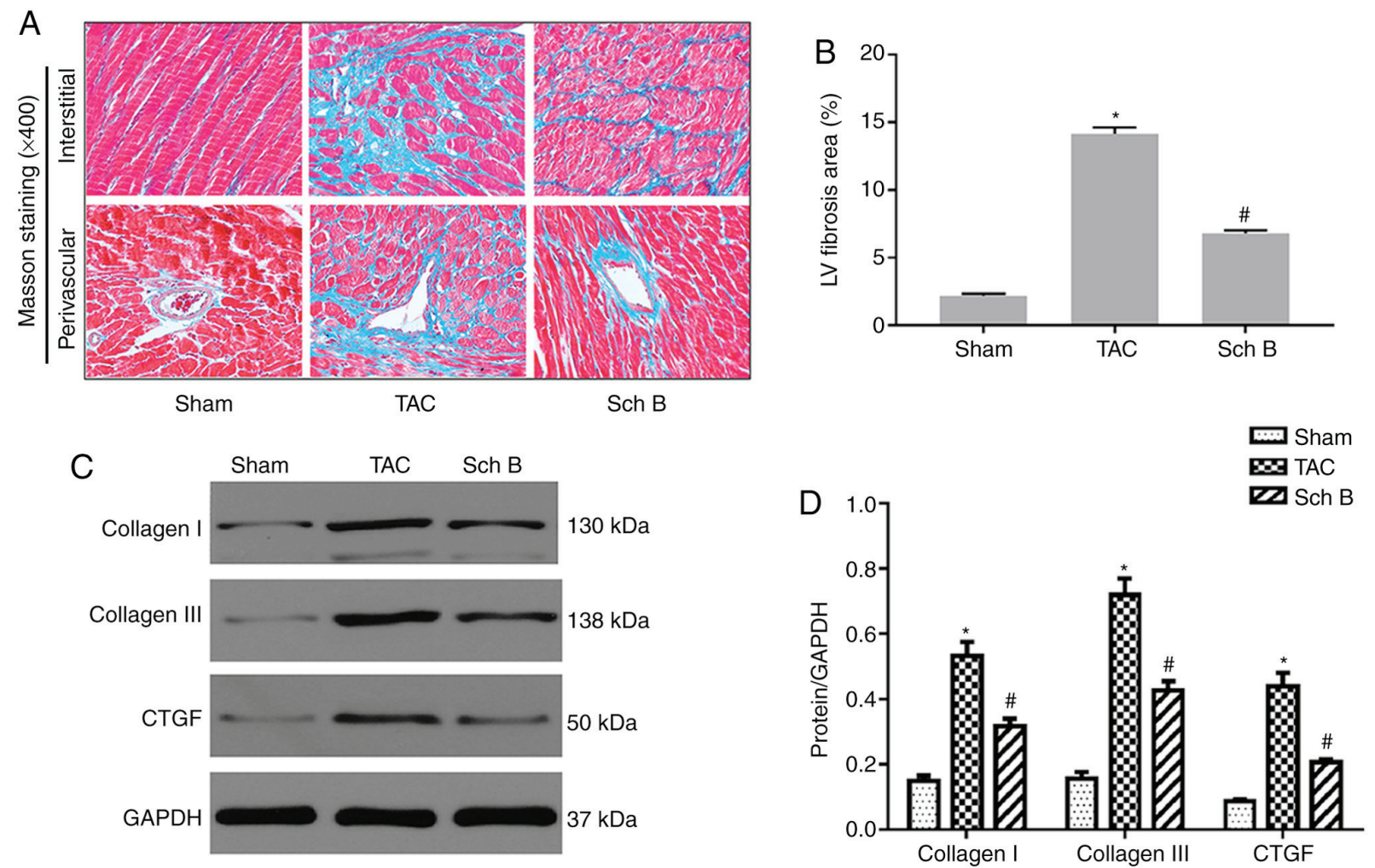

Figure 3. Myocardial fibrosis in each experimental group. (A) Representative Masson staining of myocardial tissues (magnification, x400). (B) Statistical analysis of the LV collagen volume (\%) in Masson-stained sections ( $\mathrm{n}=4)$. (C) Representative western blotting of the cardiac fibrosis markers CTGF, collagen I and III in each group. (D) Representative statistical analysis of the cardiac fibrosis markers CTGF, collagen I and III in each group ( $\mathrm{n}=4)$. Data are expressed as the mean \pm SEM. " $\mathrm{P}<0.05$ vs. respective sham group; ${ }^{\prime \prime} \mathrm{P}<0.05$ vs. respective TAC group. LV, left ventricular; CTGF, connective tissue growth factor; TAC, transverse aortic constriction; Sch B, schisandrin B. 

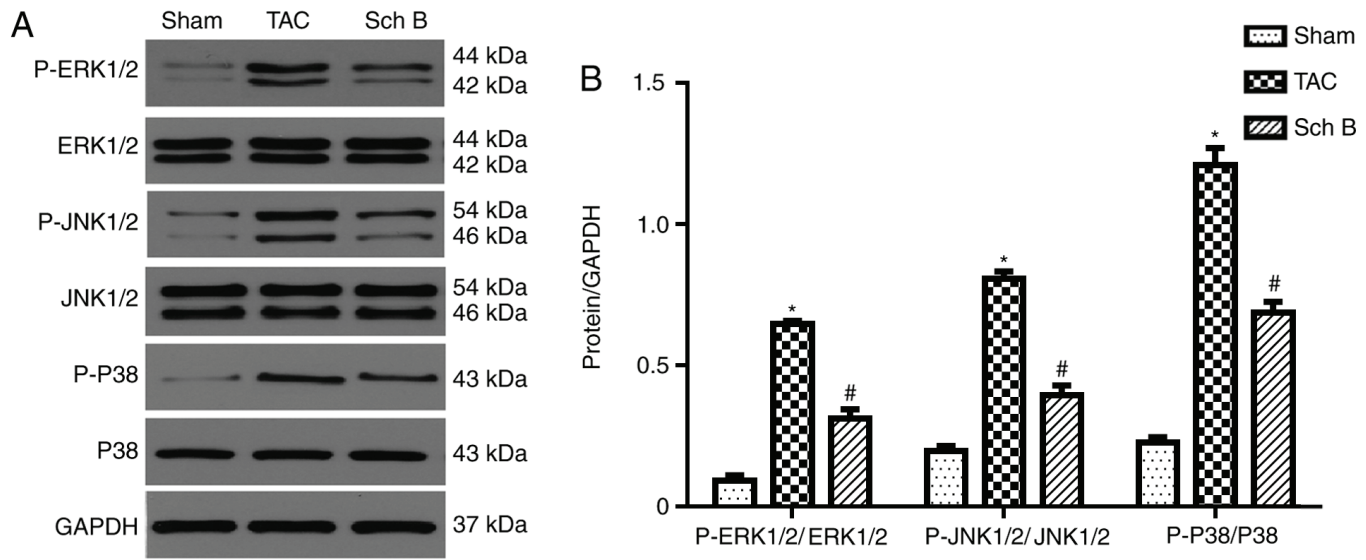

Figure 4. Sch B improves cardiac remodeling by regulating the mitogen-activated protein kinase signaling pathway in vivo. (A) Representative western blotting of ERK1/2, JNK1/2 and P38 in each experimental group. (B) Representative statistical analysis of P-ERK1/2, P-JNK1/2 and P-P38 in each experimental group $(\mathrm{n}=4)$. Data are expressed as the mean \pm standard error of the mean. ${ }^{*} \mathrm{P}<0.05$ vs. the sham group; ${ }^{*} \mathrm{P}<0.05$ vs. the TAC group. Sch $\mathrm{B}$, schisandrin $\mathrm{B}$; ERK, extracellular signal-regulated kinase; JNK, c-Jun N-terminal kinase; P38, P38 mitogen-activated protein kinase; TAC, transverse aortic constriction; p, phosphorylated.
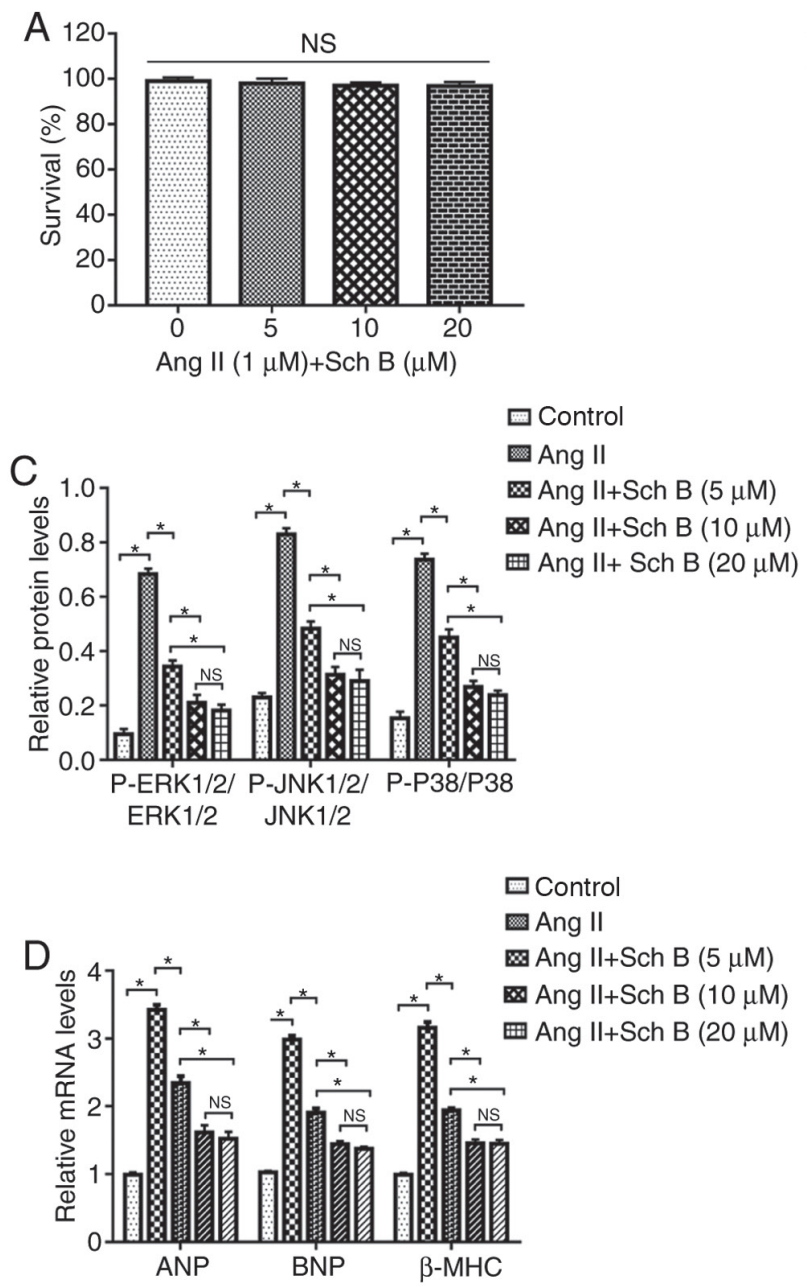

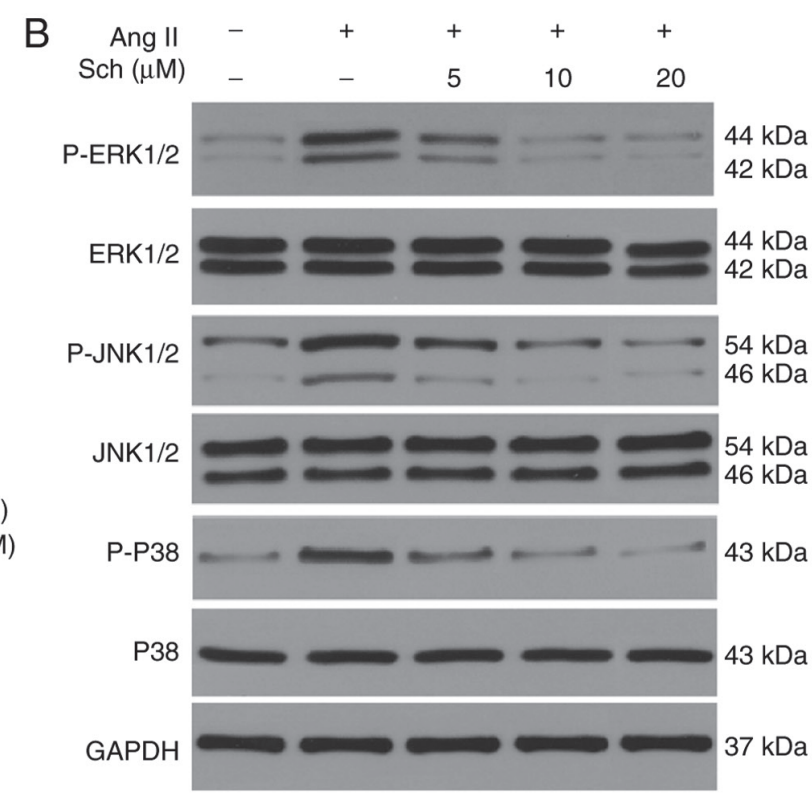

罗 Control

푬 Ang II

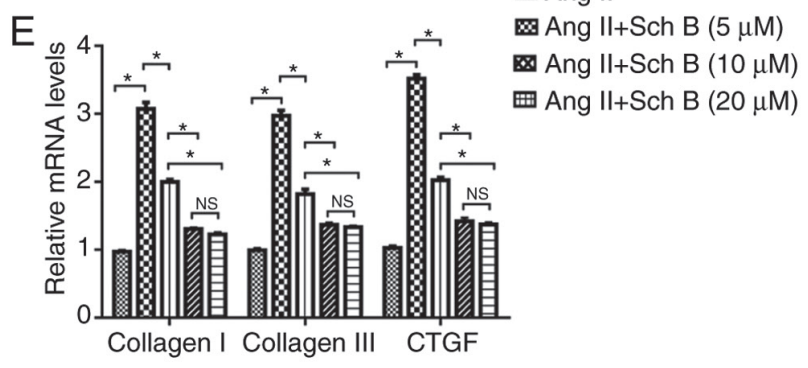

Figure 5. Sch B rescues the adverse effects of Ang II-induced myocyte hypertrophy and fibrosis by inhibiting the mitogen-activated protein kinase signaling pathway. (A) Cell viability was determined by MTT assay. (B) Representative western blotting of ERK1/2, JNK1/2 and P38 in H9c2 cells incubated with different concentrations of Sch B following exposure to Ang II. (C) Representative statistical analysis of ERK1/2, JNK1/2 and P38 in H9c2 cells incubated with different concentrations of Sch B following exposure to Ang II $(n=4)$. DMSO was used as a control solution. (D) RT-qPCR analysis of the mRNA levels of ANP, BNP and $\beta-\mathrm{MHC}$ in $\mathrm{H} 9 \mathrm{c} 2$ cells incubated with different concentrations of Sch B following exposure to Ang II (n=4). DMSO was used as a control solution. (E) RT-qPCR analysis of the mRNA levels of CTGF and collagen I and III in H9c2 cells incubated with different concentrations of Sch B following exposure to Ang II $(n=4)$. DMSO was used as a control solution. Data are expressed as the mean \pm standard error of the mean. " $\mathrm{P}<0.05$. Sch $\mathrm{B}$, schisandrin $\mathrm{B}$; Ang II, angiotensin II; ERK, extracellular signal-regulated kinase; JNK, c-Jun N-terminal kinase; P38, P38 mitogen-activated protein kinase; RT-qPCR, reverse-transcription quantitative PCR; ANP, atrial natriuretic peptide; BNP, brain natriuretic peptide; $\beta$-MHC, beta-myosin heavy chain; CTGF, connective tissue growth factor; NS, not significant; p, phosphorylated. 


\section{Discussion}

The results obtained in the current study revealed that Sch B significantly improved cardiac dysfunction in pressure overload-induced cardiac remodeling, potentially by decreasing cardiac hypertrophy and fibrosis. This effect may be due to inhibition of the MAPK signaling pathway by decreasing the phosphorylation levels of ERK1/2, JNK1/2 and P38.

Previous studies demonstrated that $\mathrm{Sch} \mathrm{B}$ has a protective effect on myocardial injury. Chiu et al (15) demonstrated that Sch B improves myocardial ischemia-reperfusion injury in rats by inducing the expression of heat shock protein (HSP) 25 and HSP 70. Moreover, a previous study also indicated that Sch B ameliorates cardiac dysfunction in a mouse model of myocardial infarction (14). These observations are consistent with studies by Thandavarayan et al (13) showing that Sch B prevents doxorubicin-induced cardiac dysfunction. The present study provides correlative evidence suggesting that compared with the TAC group, the LVEF and LVFS in the Sch B-treated group were significantly increased. Therefore, Sch B may alleviate pressure overload-induced cardiac dysfunction.

The main pathological changes in pressure overloadinduced pathological myocardial remodeling include myocardial cell hypertrophy and myocardial fibrosis (23). Cardiomyocyte hypertrophy is one of the hallmark changes in pathological myocardial remodeling (24). The present study revealed that cardiomyocyte CSA was significantly increased in the TAC group compared with the sham group. Following 4 weeks of treatment with Sch B, the CSA of cardiomyocytes was significantly reduced compared with the other groups. Similarly, the Sch B-treated group exhibited significantly lower levels of cardiac hypertrophy markers compared with the TAC group. In addition, the HW/BW, HW/TL and LW/BW of the Sch B-treated group were decreased compared with the TAC group. Therefore, the results obtained in the current study revealed that Sch B may improve pressure overload-induced cardiac hypertrophy.

Myocardial fibrosis is another hallmark of pathological myocardial remodeling (25). Excessive deposition of cardiac collagen results in diastolic and contractile dysfunction, leading to heart failure (26). Previous studies demonstrated that Sch B attenuates pathological liver, pulmonary and epidural fibrosis (27-29). A previous study indicated that Sch B improves cardiac fibrosis in a mouse model of myocardial infarction (14). Similar results were observed in the present study. Compared with the TAC group, the Sch B-treated group exhibited a significantly reduced myocardial fibrosis area, and the expression of myocardial fibrosis markers (CTGF, collagen I and 9+65 III) was significantly reduced. Therefore, Sch B may significantly improve myocardial fibrosis caused by TAC.

Previous studies have revealed that the MAPK signaling pathway is closely associated with cardiac pathology, including cardiac hypertrophy and myocardial fibrosis $(30,31)$. Activation of ERK1/2, P38 and JNK1/2 increases cell growth and migration and promotes myocardial fibrosis $(30,31)$. In addition, previous studies revealed that Sch B inhibits the MAPK signaling pathway $(13,32,33)$. Activation of ERK1/2, JNK1/2 and P38 increases cell growth and migration and promotes myocardial fibrosis (30). A previous study revealed that Sch B prevents doxorubicin-induced cardiac damage by inhibiting the MAPK signaling pathway (10). These findings are similar to the results of the present study. Compared with the TAC group, the phosphorylation levels of ERK1/2, JNK1/2 and P38 in the Sch B-treated group were significantly decreased. This was associated with less cardiac hypertrophy and myocardial fibrosis in the Sch B-treated group. Moreover, the in vitro experiments in the current study further suggested that Sch B alleviated Ang II-induced cardiac fibrosis and hypertrophy by decreasing the phosphorylation levels of ERK1/2, JNK1/2 and P38. Similarly, a number of previously published studies demonstrated that Sch B prevents cardiac damage via suppression of the MAPK signal pathway $(13,31,32)$.

The current study had a number of limitations. The present study revealed that Sch B may prevent pressure overload-induced cardiac fibrosis and hypertrophy by inhibition of the MAPK signaling pathway. Future experiments should use small interfering RNA or inhibitors of the MAPK pathway to further verify the role of MAPK in the protective effect of Sch B. Whether the MAPK signaling pathway is a direct target of Sch B remains unclear. Further studies are required to elucidate the mechanism by which Sch B regulates the MAPK signaling pathway.

In conclusion, the present study demonstrated that Sch B may improve pathological myocardial remodeling and cardiac function induced by pressure overload through inhibition of the MAPK signaling pathway.

\section{Acknowledgements}

Not applicable.

\section{Funding}

No funding was received.

\section{Availability of data and materials}

The datasets used and/or analyzed during the current study are available from the corresponding author on reasonable request.

\section{Authors' contributions}

FA, QHG, XG and ZC designed the study. FA, QHG and BY performed the experiments. FA, QHG and WL performed data analysis and interpreted the data. FA, QHG, BY and WL built the model and analyzed data. XG and ZC wrote the manuscript. All authors read and approved the final manuscript.

\section{Ethics approval and consent to participate}

The use of animals in the present study was reviewed and approved by the Ethics Committee of the Central Hospital of Wuhan (Wuhan, China).

\section{Patient consent for publication}

Not applicable. 


\section{Competing interests}

The authors declare that they have no competing interests.

\section{References}

1. Metra M and Teerlink JR: Heart failure. Lancet 390: 1981-1995, 2017.

2. Burchfield JS, Xie M and Hill JA: Pathological ventricular remodeling: Mechanisms: Part 1 of 2. Circulation 128: 388-400, 2013.

3. Opie LH, Commerford PJ, Gersh BJ and Pfeffer MA: Controversies in ventricular remodelling. Lancet 367: 356-367, 2006.

4. Drazner MH: The progression of hypertensive heart disease Circulation 123: 327-334, 2011

5. Houser SR, Margulies KB, Murphy AM, Spinale FG, Francis GS, Prabhu SD, Rockman HA, Kass DA, Molkentin JD, Sussman MA, et al: Animal models of heart failure: A scientific statement from the american heart association. Circ Res 111: 131-150, 2012

6. Shimizu I and Minamino T: Physiological and pathological cardiac hypertrophy. J Mol Cell Cardiol 97: 245-262, 2016.

7. Heineke J and Molkentin JD: Regulation of cardiac hypertrophy by intracellular signalling pathways. Nature reviews. Nat Rev Mol Cell Biol 7: 589-600, 2006.

8. Tham YK, Bernardo BC, Ooi JY, Weeks KL and McMullen JR: Pathophysiology of cardiac hypertrophy and heart failure: Signaling pathways and novel therapeutic targets. Arch Toxicol 89: 1401-1438, 2015.

9. Panossian A and Wikman G: Pharmacology of schisandra chinensis bail: An overview of Russian research and uses in medicine. J Ethnopharmacol 118: 183-212, 2008

10. Ip SP, Poon MK, Wu SS, Che CT, Ng KH, Kong YC and Ko KM: Effect of schisandrin B on hepatic glutathione antioxidant system in mice: Protection against carbon tetrachloride toxicity. Planta Med 61: 398-401, 1995

11. Checker R, Patwardhan RS, Sharma D, Menon J, Thoh M, Bhilwade HN, Konishi T and Sandur SK: Schisandrin B exhibits anti-inflammatory activity through modulation of the redox-sensitive transcription factors Nrf2 and NF- $\kappa \mathrm{B}$. Free Radic Biol Med 53: 1421-1430, 2012.

12. Xu Y, Liu Z, Sun J, Pan Q, Sun F, Yan Z and Hu X: Schisandrin B prevents doxorubicin-induced chronic cardiotoxicity and enhances its anticancer activity in vivo. PLoS One 6: e28335, 2011.

13. Thandavarayan RA, Giridharan VV, Arumugam S, Suzuki K, Ko KM, Krishnamurthy P, Watanabe $\mathrm{K}$ and Konishi T: Schisandrin B prevents doxorubicin induced cardiac dysfunction by modulation of DNA damage, oxidative stress and inflammation through inhibition of MAPK/p53 signaling. PLoS One 10: e0119214, 2015.

14. Chen P, Pang S, Yang N, Meng H, Liu J, Zhou N, Zhang M, Xu Z, Gao W, Chen B, et al: Beneficial effects of schisandrin B on the cardiac function in mice model of myocardial infarction. PLoS One 8: e79418, 2013.

15. Chiu PY and Ko KM: Schisandrin B protects myocardial ischemia-reperfusion injury partly by inducing Hsp25 and Hsp70 expression in rats. Mol Cell Biochem 266: 139-144, 2004.

16. Zhang W, Sun Z and Meng F: Schisandrin B ameliorates myocardial ischemia/reperfusion injury through attenuation of endoplasmic reticulum stress-induced apoptosis Inflammation 40: 1903-1911, 2017.

17. Liu Y, Jiang XL, Liu Y, Jiang DS, Zhang Y, Zhang R, Chen Y, Yang Q, Zhang XD, Fan GC and Li H: Toll-interacting protein (Tollip) negatively regulates pressure overload-induced ventricular hypertrophy in mice. Cardiovasc Res 101: 87-96, 2014.

18. Wang Z, You L, Cheng Y, Hu K, Wang Z, Cheng Y, Yang J, Yang Y and Wang G: Investigation of pharmacokinetics, tissue distribution and excretion of schisandrin B in rats by HPLC-MS/MS Biomed Chromatogr 32, 2018.
19. Ko KM, Chen N, Leung HY, Leong EP, Poon MK and Chiu PY: Long-term schisandrin $\mathrm{B}$ treatment mitigates age-related impairments in mitochondrial antioxidant status and functional ability in various tissues, and improves the survival of aging C57BL/6J mice. Biofactors 34: 331-342, 2008.

20. Leong PK, Chiu PY and Ko KM: Prooxidant-induced glutathione antioxidant response in vitro and in vivo: A comparative study between schisandrin B and curcumin. Biol Pharm Bull 35 464-472, 2012

21. Chiu PY and Ko KM: Schisandrin B-induced increase in cellular glutathione level and protection against oxidant injury are mediated by the enhancement of glutathione synthesis and regeneration in AML12 and $\mathrm{H} 9 \mathrm{c} 2$ cells. Biofactors 26: 221-230, 2006.

22. Livak KJ and Schmittgen TD: Analysis of relative gene expression data using real-time quantitative PCR and the 2(-Delta Delta $\mathrm{C}(\mathrm{T})$ ) method. Methods 25: 402-408, 2001.

23. Beetz N, Rommel C, Schnick T, Neumann E, Lother A, Monroy-Ordonez EB, Zeeb M, Preissl S, Gilsbach R, Melchior-Becker A, et al: Ablation of biglycan attenuates cardiac hypertrophy and fibrosis after left ventricular pressure overload. J Mol Cell Cardiol 101: 145-155, 2016.

24. Zhai M, Liu Z, Zhang B, Jing L, Li B, Li K, Chen X, Zhang M, $\mathrm{Yu} \mathrm{B}$, Ren K, et al: Melatonin protects against the pathological cardiac hypertrophy induced by transverse aortic constriction through activating PGC-1beta: In vivo and in vitro studies. J Pineal Res 63, 2017.

25. Moens AL, Takimoto E, Tocchetti CG, Chakir K, Bedja D, Cormaci G, Ketner EA, Majmudar M, Gabrielson K, Halushka MK, et al: Reversal of cardiac hypertrophy and fibrosis from pressure overload by tetrahydrobiopterin: Efficacy of recoupling nitric oxide synthase as a therapeutic strategy. Circulation 117: 2626-2636, 2008.

26. Urban ML, Manenti L and Vaglio A: Fibrosis-A common pathway to organ injury and failure. N Engl J Med 373: 95-96, 2015.

27. Chen Q, Zhang H, Cao Y, Li Y, Sun S, Zhang J and Zhang G: Schisandrin $\mathrm{B}$ attenuates $\mathrm{CCl}_{4}$-induced liver fibrosis in rats by regulation of Nrf2-ARE and TGF- $\beta /$ Smad signaling pathways Drug Des Devel Ther 11: 2179-2191, 2017.

28. Zhang D, Liu B, Cao B, Wei F, Yu X, Li GF, Chen H, Wei LQ and Wang PL: Synergistic protection of Schizandrin B and Glycyrrhizic acid against bleomycin-induced pulmonary fibrosis by inhibiting TGF- $\beta 1 / \mathrm{Smad} 2$ pathways and overexpression of NOX4. Int Immunopharmacol 48: 67-75, 2017.

29. Jin H, Wang Z, Gu Z, Wu J, Bai X, Shao Z, Miao J, Wang Q, Wang Q and Wang X: Schisandrin B attenuates epidural fibrosis in postlaminectomy rats by inhibiting proliferation and extracellular matrix production of fibroblasts. Phytother Res 33: 107-116, 2019.

30. Hunter JJ, Tanaka N, Rockman HA, Ross J Jr and Chien KR Ventricular expression of a MLC-2v-ras fusion gene induces cardiac hypertrophy and selective diastolic dysfunction in transgenic mice. J Biol Chem 270: 23173-23178, 1995.

31. Cowan KJ and Storey KB: Mitogen-activated protein kinases: New signaling pathways functioning in cellular responses to environmental stress. J Exp Biol 206: 1107-1115, 2003.

32. Ran J, Ma C, Xu K, Xu L, He Y, Moqbel SAA, Hu P, Jiang L, Chen W, Bao J, et al: Schisandrin B ameliorated chondrocytes inflammation and osteoarthritis via suppression of NF- $\mathrm{BB}$ and MAPK signal pathways. Drug Des Devel Ther 12: 1195-1204, 2018.

33. Park EJ, Chun JN, Kim SH, Kim CY, Lee HJ, Kim HK, Park JK, Lee SW, So I and Jeon JH: Schisandrin B suppresses TGFbetal signaling by inhibiting Smad2/3 and MAPK pathways. Biochem Pharmacol 83: 378-384, 2012

This work is licensed under a Creative Commons Attribution-NonCommercial-NoDerivatives 4.0 International (CC BY-NC-ND 4.0) License. 